\title{
ENCONTROS POTENTES PRODUZIDOS PELA INVESTIGAÇÃO COM HISTÓRIAS DE VIDA
}

\section{VALESKA FORTES DE OLIVEIRA}

http:/orcid.org/0000-0002-8295-1007

Universidade Federal de Santa Maria

\section{TANIA MICHELINE MIORANDO}

http:/orcid.org/0000-0003-2934-5478

Universidade Federal de Santa Maria

Este artigo percorre pelas trilhas das histórias de vida como caminhos investigativos na formação profissional de professores. Por objetivo, trouxemos como proposição apresentar as vertentes metodológicas, matrizes da pesquisa, a partir das histórias de vida de professores e suas potentes indicações para pensar a formação docente. Para mostrar um cenário que aproxima as vivências dos professores das discussões da formação profissional, apontamos qualitativamente, o transcurso desde as primeiras investigações até seus desdobramentos e hoje, ao relatar como se inaugurou um novo fazer na pesquisa. Observamos que, somente após nos debruçarmos a compor a trajetória que estas pesquisas tomaram, é possivel traçar indicações a encontrar suas tendências no campo por ele aberto. $O$ seu conjunto traçou uma breve recomposição do início da pesquisa, que buscou conhecer as histórias de vidas dos professores e conta como hoje os pesquisadores já se arriscam em caminhos criativos para pensar a formação de professores pela voz que relata os fazeres docentes no percurso profissional.

Palavras-chave: História de vida. Pesquisa (auto)biográfica. Formação de professores.

\section{ABSTRACT POWERFUL MEETINGS PRODUCED BY RESEARCH WITH LIFE STORIES}

This article travels along the path of life stories as investigative paths in the professional formation of teachers. Our objective is to present the methodological aspects, the research matrix, from the teachers' life histories and their powerful indications for thinking about teacher education. To show a scenario that brings teachers' experiences 
closer to the discussions of vocational training, we qualitatively point out the course from the first investigations to their unfolding and today, when reporting how a new doing in research was inaugurated. We observe that, only after we look at composing the trajectory that these researches took, it is possible to trace indications to find their tendencies in the field opened by it. Their set outlined a brief recomposition of the beginning of the research, which sought to know the teachers' life stories and tells how researchers are now venturing in creative ways to think about the formation of teachers through the voice that reports the teaching activities in the professional career.

Keywords: Life's history. (Auto)biographical research. Teacher training.

\section{RESUMEN ENCUENTROS SIGNIFICATIVOS PRODUCIDOS POR LA INVESTIGACIÓN CON HISTORIAS DE VIDA}

Este artículo recorre el camino de las historias de vida como caminos de investigación en la formación profesional de los docentes. Nuestro objetivo es presentar los aspectos metodológicos, la matriz de investigación, a partir de las historias de vida de los docentes y sus poderosas indicaciones para pensar en la formación docente. Para mostrar un escenario que acerque las experiencias de los docentes a las discusiones sobre la formación profesional, señalamos cualitativamente el curso desde las primeras investigaciones hasta su desarrollo y hoy, cuando informamos cómo se inauguró un nuevo hacer en la investigación. Observamos que, solo después de analizar la composición de la trayectoria que tomaron estas investigaciones, es posible rastrear indicaciones para encontrar sus tendencias en el campo abierto por él. Su conjunto describió una breve recomposición del comienzo de la investigación, que buscaba conocer las historias de vida de los docentes y cuenta cómo los investigadores ahora se están aventurando de manera creativa para pensar en la formación de docentes a través de la voz que informa sobre las actividades docentes en la carrera profesional.

Palabras clave: Historia de vida. (Auto)investigación biográfica. Formación de profesores.

Nenhuma aprendizagem evita a viagem. Sob a orientação de um guia, a educação empurra para o exterior. Parte: sai. Sai do ventre de tua mãe, do berço, da sombra oferecida pela casa paterna e as paisagens juvenis. Ao vento e à chuva: lá fora, faltam todos os abrigos. As tuas ideias iniciais não repetem senão palavras antigas. Jovem: velho tagarela. A viagem dos filhos, eis o sentido despido da palavra grega pedagogia. Aprender provoca a errância. (SERRES, 1993, p. 23) 


\section{Primeiras palavras e nossas aproximações}

A vida e o seu enredo se desenrolam em uma grande sequência de pequenos relatos que, encadeados, produzem um romance que transpassa boa parte de nossas histórias. Em cada relato escolhemos mostrar partes que significadas pelo tom que damos a ela, apropria sentidos que passam a dizer quem somos: professoras/professores, estudantes, trabalhadoras/trabalhadores, pesquisadoras/ pesquisadores... Identificamos o sujeito que há no relato produzindo-se em uma história: sentidos potentes de vidas que se repetem, se diferenciam, se tornam coletivos, se olham e se contam.

As histórias de vida, que amealhamos em pequenos pedaços diários de recontos do cotidiano, dizem de uma enciclopédia plena de significações. Às vezes, pedacinhos dela parecem escondidas no corriqueiro, como se pudéssemos transformar em hábito a vida ou deixar passar como se fosse banal ter dia a dia uma vida por viver. Mas quando falamos sobre cada episódio, esses pedacinhos parecem coloridos de novo, prontos para serem reconhecidos em palavras e ressignificados como quando olhamos através de um espelho e as imagens contam sonhos em perspectiva - do passado, do presente e como ainda pretendemos viver, irrequietos.

Ao nos aproximarmos das histórias de vida na educação, quisemos notar existências em relatos autorais dos professores que inscrevem uma pedagogia que se formula no seu cotidiano. Passamos a conhecer histórias incorporadas de autores que já descreveram o fazer didático para os cursos de licenciatura e estes, que ainda argumentam uma incompreensão entre teorias já impressas e hipóteses que ainda buscam palavras para serem registradas. Um relato de história de vida é como sair em viagem, diz Serres (1993), é sair a caminhar para si, contou Josso (2004), são as relações que atravessam as vidas, lembra Nóvoa (1995), pintam um Imaginário coletivo, atenta Castoriadis (1982), num cenário que reinterpretamos sem muito esforço para compreender, mas viver nele.

A história do Gepeis (Grupo de Estudos e Pesquisas em Educação e Imaginário Social), é contada pelas tramas das histórias de vidas de professores em formação inicial, em formação continuada, projetos de extensão, ensino e pesquisa. Sentamos em rodas de estudos, de conversas, de pesquisas, em perfomances artísticas e sessões de cinema. Fazemos piqueniques literários que nos ajudam a dar a leveza e a poética para suportar dias de dureza, tristeza, frustração, em estar corajosamente resistindo entre o que a vida leva e o que a profissão pede. Ouvimos Coisas ${ }^{1}$ desde 2010 e repensamos nossos espaços e fazeres na Educação.

Há mais de duas décadas ouvindo histórias de professores, contando suas vidas, reconhecendo nossas histórias, encontrando sentidos e ressignificando, buscamos palavras, buscamos caminhos. Mais que uma vez ouvi-las, inventamos tempos e identificamos as expressões que se multiplicam em intenções, sensibilidade, criatividade. Tramamos em parcerias com autores que já há muito fazem isso (NÓVOA; FINGER, 1988; ABRAHÃO, 2004; DELORYMOMBERGER, 2008; PASSEGGI; SOUZA, 2008) e nos ensinam a encontrar palavras para os nossos estudos. Entremeio teorias, pontuamos nossos espaços, assumindo o direito de constituirmos uma docência feminina cujas narra-

1 O Ouvindo Coisas é um evento que o Gepeis promove junto ao Centro de Educação, na UFSM, para falar de Educação e todo seu contexto, procurando fugir do formato de grandes eventos e a formalidade que poderia afastar os participantes, organizadores e mediadores. O site que guarda as memórias dos eventos que já aconteceram é http://coral.ufsm.br/gepeis/index.php/ouvindo-coisas. 
tivas expandem territórios menos submissos e mais resistentes.

Atravessamos tempos políticos que mexem nos imaginários instaurados, instituídos, reduzidos a uma compreensão dada de uma vida para uma profissão: ser professora/professor. Também aqui temos a companhia de autores que não nos deixam sozinhos quando vemos que os horizontes se ampliam e o mundo torna-se ainda mais diverso daquele que pensávamos conhecer. Entramos para tempos - políticos e de vida - que exigem movimentos de um protagonismo que nos faz sujeitos nos espaços em que marcamos presença.

A chamada de sala de aula, convocando a presença, muda de lado, mas não libera o comparecimento: “Chegou o tempo de repensar a investigação educacional numa perspectiva mais ampla, com uma liberdade sem condição. Porque a liberdade é tudo, e tudo o resto é nada" (NÓVOA, 2014, p. 20). Mas como compreender este chamamento tão provocativo? De onde tirar forças e coragem para assumir a liberdade a que temos conquistado em nossos fazeres docentes, que estudamos perfazendo em brincadeiras poéticas as teorias para a docência?

Encontramos nos autores das Histórias de Vida um refúgio para pensar a docência e sua formação profissional como um desenvolvimento a se constituir negando "modelos formativos pensados para os professores e não com eles, muitas vezes, [que] não levantam questões de fundo para pensar no professor e na docência na sociedade contemporânea" (OLIVEIRA, 2016, p. 9). Por aproximar os pesquisadores aos professores, é muito mais possivel pensar com os professores quando os conhecemos ou sabemos de suas condições, suas dificuldades e seus sonhos. Como fazer isso senão ouvindo-os a contar, enquanto pensam suas vidas e sua profissão?

A aproximação à História de Vida deixounos reinventar a pesquisa, lembrando que suas histórias constituíram suas vidas e se materializam em uma parte importante da investigação sobre os professores - agora conversando lado a lado. Encontramos um sujeito da educação para além de teorias a serem consideradas em suas práticas. Ouvir mais vezes a mesma história, reler anotações não transcritas por uma entrevista, mas por silêncios, lágrimas, raivas, emoções que, por mais que saibamos que vão aparecer, não há um pesquisador totalmente preparado - porque trata de vida, do inesperado.

Os relatos vêm cheios de atravessamentos culturais, políticos e sociais de seus tempos, que mexem profundamente nas suas e em outras vidas. Para fins de pesquisa, somente depois de um conjunto de histórias que parecem passar sem fatos especiais, se percebe 0 Imaginário que nele estava constituído. A vida matizada de um sentido corriqueiro esmaece confundida com o habitual - sem perceber que ali é que ela mostra um grande mapa de condições para tentar estabilizar as mudanças. Avivar os constructos diários que saltam pela diferença, mas pouco sobressaem-se por estarem restritos à sala de aula ou à escola, abranda os movimentos instituintes (CASTORIADIS, 1982) que procuram sobressair ao instituído.

Está no Imaginário Social que os professores na escola têm a responsabilidade de mudar a Educação das sociedades. Mas esta máxima transfere do Estado para o indivíduo uma responsabilidade que não pode ser compreendida sem a complexidade (MORIN, 2001) que abrange. Os professores carregam o peso de salvar uma sociedade com suas aulas, mas não são vistos por esta mesma sociedade o quanto estão sozinhos fazendo uma educação imaginada. Escolhe-se um cenário que emerge sem contexto: a escola e os professores vivem em uma sociedade que ainda pouco percebe o quanto a mídia, a gestão administrativa e a 
cidade, por exemplo, também educam (ou deseducam) para a missão esperada de uma sociedade que alcance sair da barbárie.

O contexto de uma escola cujos professores voltam diariamente para o trabalho e não conseguem viver dele em condições de escolher para si oportunidades que profissões que melhor remuneram oferecem, vem traduzido em suas falas - muitas vezes tristes e sem sonhos, de uma educação cansada. Voltar para uma escola cujos projetos e infraestrutura está sem financiamento, com poucas condições de investir na formação de seu quadro funcional, requer palavras que se seguram nas alegrias relatadas dos aprendizados e homenagens que recebem ao longo de seus dias.

As teorias da educação quando não incorporam as vidas de seus professores nos seus fazeres pedagógicos, pouco transformam pelos argumentos que trazem. Nas histórias de vida que os professores narram, as teorias vêm preenchidas de sentidos nos seus fazeres pedagógicos: prenhes de sentimentos - esperados ou não pelas descrições teóricas para a docência. Movimentos de vida que mostram uma estética da docência (MIORANDO, 2018), dizendo de uma professoralidade (PEREIRA, 2013) que se renova a cada fase que muda sua trajetória pessoal e profissional.

A partir das histórias de muitas vidas que passamos a considerar, foi reiterado o que os professores dizem ao querer mais espaço para a música, o cinema, a arte, em suas aulas, mas que nem sempre há espaço dentro dos sistemas, num primeiro olhar. Percebemos que os professores contavam de suas práticas e de suas vidas dizendo desses aprendizados que, estrategicamente, entravam para a sala de aula, saíam para o pátio, passeavam por outras escolas, dialogavam junto aos colegas. 0 conjunto de tantas histórias recolhidas mostram um imaginário coletivo que se constitui e fica sendo registrado.
Os professores que foram construindo as histórias das escolas recolhem episódios marcantes e, pelos relatos, poucas vezes tiveram a oportunidade de deixar registrado. Ao receberem aqueles que vêm começar a atuar, iniciando suas carreiras docentes, trazem a vontade de contar tudo e falar do que concluíram ao final de suas carreiras: há muitas camadas de aprendizados, alegrias, frustrações, ressentimentos e esperanças. Por sua vez, os colegas recém chegados trazem sonhos, cautela ao agir, lembranças de seus professores e de suas aulas de formação.

Ao recolher essas falas em tempos de vida muito diferentes, dispor em estudos que mostram de qual escola estamos falando, percebese um conjunto de discursos que se refazem: trajetórias percorridas que deixam vestígios e provocam encorajamentos a novas trilhas - mesmo que não sejam recomendadas, mas ousadas a investir em possibilidades que possam se reinventar. 0 cruzamento de tantas histórias se mesclam em narrativas de formação.

\section{A Pesquisa em Educação}

Retomamos as palavras finais do texto intitulado "Em busca da liberdade nas universidades: para que serve a investigação em Educação?" (NÓVOA, 2015), publicado na Revista Lusófona de Educação, para um exercício de pensamento porque é necessário retomar. Mais ainda, retomar para avaliar. Avaliar para um balanço de até onde viemos e, mais radicalmente para tentar responder a questão levantada acima: para que tem servido a investigação em educação na perspectiva narrativa, das histórias de vida ou como foi inaugurado no Brasil o "movimento (auto)biográfico" (PASSEGGI; SOUZA, 2017).

Trazemos, brevemente, a rememoração dos momentos iniciais e corajosos do GEDOMGE que se lançava a fazer pesquisa acreditando 
em um movimento que emergia no contexto da pesquisa. Essas investigações, por sua vez, traziam pessoas a falar, contando suas memórias e como se perceberam em meio a um cotidiano que, por vezes, invisibiliza e quase apaga o que foi notícia ao longo dos dias. No movimento que se instaurava, pesquisadores acreditaram na voz dos próprios protagonistas com suas histórias de força que faziam a diferença entre os seus pares.

O momento inaugural em Educação acontece nos anos 1990, com os trabalhos e pesquisas desenvolvidos pelo Grupo de Estudos Docência, Memória e Gênero (GEDOMGE), criado em 1994, na Faculdade de Educação da Universidade de São Paulo (FEUSP). Esses estudos inspiram-se, prioritariamente, do movimento sociohistórico das histórias de vida em formação. Essa é a primeira filiação do movimento (auto)biográfico em Educação, no Brasil. (PASSEGGI; SOUZA, 2017, p. 13. Grifos dos autores.)

Esse momento inicial, mas nada de principiante em pesquisa, mostra a exaustão que a pesquisa em educação já mostrava de como vinha sendo feita e o desafio para a tomada de decisão para os rumos a ver outra possibilidade de investigação, junto com professores. Retomar esse momento nos dá forças para inaugurar dentro dessa condição de pesquisador que investiga por esta vertente, buscar o que ainda não foi feito.

Quando em outros momentos todos os inspiradores foram estrangeiros, hoje passamos a contabilizar um grupo grande de pesquisadores brasileiros a avançar para conhecer a escola e a docência pelos dizeres a partir dos cenários que os próprios professores referem e quais palavras escolhem para suas narrativas. Estes autores que ainda lemos, continuam impulsionadores na compreensão de como fazer a pesquisa com professores, mas mais que isso, tomamos de sua coragem a força para constituirmos nossas investigações.
Ele é em larga medida tributário das contribuições dos pioneiros das histórias de vida em formação, que emerge, nos anos 1980, na Europa e no Canadá, no contexto da formação continuada de adultos. Ressaltam-se os estudos de Gaston Pineau (1983, 2005); Pierre Dominicé (2000); Marie Christine Josso (2010), no mundo da francofonia e o de António Nóvoa (1992, 1995), no mundo da lusofonia. (PASSEGGI; SOUZA, 2017, p. 13. Grifos dos autores.)

Para chegar a conhecer a "formação continuada de adultos", até então, buscavam-se os delineamentos contextuais e, aos poucos, passavam a ouvir os professores, que tinham mais para relatar que o aspecto formal do aprendizado de adultos. A curvatura nos indicativos do fazer pesquisa em educação passava a mostrar a riqueza nas falas, por proporcionar a composição de elementos que transcendem nossas questões de pesquisa. Daí o exercício de não cairmos em reducionismos ao perguntar ou ouvir as falas que chegam aos nossos estudos somente nos moldes como já foram feitas.

O movimento apresentado pelas coletâneas organizadas a partir da produção lusófona, intituladas "Profissão Professor" (NÓVOA, 1995) e "Vida de Professores" (NÓVOA, 1992) foi no Brasil o que trouxe António Nóvoa para o campo da formação junto com os professores. Essa produção movimentou a pesquisa com professores em suas diferentes fases de formação, trazendo a voz dos sujeitos que eram investigados para um encontro com seus processos formativos e a história da própria profissão.

No Congresso de Educação, realizado na cidade de Santa Maria/RS, pelo Centro de Educação, da Universidade Federal - UFSM, a professora Selma Garrido Pimenta, da Faculdade de Educação, da Universidade de São Paulo, traz, em 2000, uma importante colaboração desse campo investigativo no país. Nosso contato tem início nesse mesmo ano e inclui idas 
à Universidade de Lisboa para estudos mais dirigidos. Em outros momentos, estávamos em novas parcerias cada um no país do outro para aproximar o diálogo e o estudo.

Os contatos potentes se desdobraram com a inclusão no círculo do GEPEIS, da Universidade Federal de Santa Maria, os laços de cooperação com o grupo coordenado pela professora Denice Bárbara Catani, o GEDOMGE, da Universidade de São Paulo, consultora da primeira investigação em rede do grupo. Essa primeira grande pesquisa se deu na perspectiva das narrativas de formação com professores. Iniciamos e aprofundamos investigações, dentre elas, a que intitulamos: Narrativas de Formação com Histórias de Vida, interessando-nos o processo de Memória Docente.

As leituras conceituais se enriqueciam a ampliar o olhar para a literatura e as artes. Canetti (2010) é apresentado ao grupo e ler para contar as histórias é outro elemento a ser aprendido. 0 que ler e como escrever as histórias que marcam um tempo e uma comunidade, traçou pauta para nossos repertórios. Custou-nos ver de onde vêm os enunciados políticos e como os corpos relatam, quando os silêncios das falas se enchem de palavras sem serem ditas. Este foi um grande aprendizado que não estava descrito em receituários, mas aprendidos ao serem conhecidos se a escuta sensivel (BARBIER, 2007) estivesse presente, permeando a investigação.

As intercursões que o GEPEIS experimentou deixou marcas indeléveis. A partir daí os sujeitos que estavam nas pesquisas passavam a ser reconhecidos com suas vidas: entravam para o campo epistemológico da educação para contar de sua docência, trazendo histórias. Muito desse trabalho ficou registrado no livro que publicamos: Imagens de Professor: significações do trabalho docente (OLIVEIRA, 2000). Nossos encontros foram aproximados também pelo território português.
Os professores que contavam suas histórias de vida desde a década de noventa, do século passado, foram se multiplicando. Um banco com muitas informações foi se ampliando. Algumas vidas foram se constituindo dentro do grupo e passaram a ser pensadas mediante a possibilidade de formar-se para a docência ressignificando as memórias de vida. E outras, depois de terem sido dadas a conhecer, continuaram seus percursos sem mais voltarem ao grupo ou o grupo a reencontrá-las: algumas seguiram a formação, outras, aposentaram-se e outras, seguiram a docência, mas nunca mais igual a antes.

A liberdade que produziu um imaginário no Brasil sobre a produção de António Nóvoa, relacionando-o com a formação de professores, foi diferente do que era conhecido em terras portuguesas, que já perfaziam uma segunda vertente desta forma de pesquisa. Lá deu-se pela investigação em história da educação, com o olhar voltado para o cenário da produção à pesquisa (auto)biográfica no campo educacional.

Os trabalhos desenvolvidos sob esse enfoque voltam-se, como já afirmamos, para a formação docente, e se situam, prioritariamente, na segunda vertente da pesquisa (auto)biográfi$\mathrm{ca}$, recorrendo às histórias de vida e às narrativas autobiográficas como fonte e método de investigação qualitativa, indagando-se sobre práticas docentes, as trajetórias de formação, não apenas para produzir conhecimento sobre essas práticas, mas perceber como os professores dão sentido a elas. (PASSEGGI; SOUZA, 2017, p. 13)

Essa vertente inspirou os trabalhos dos pesquisadores em educação, no Brasil, e seguiram fortemente para a formação de professores. Abrimos os planejamentos, os diários de classe, pela mão do professor, que trouxe seus cadernos de outras épocas. Seguimos ouvindo seus sonhos, frustrações e significações dentros dos espaços escolares, 
chamando de investigações a aproximação ao campo da formação. As narrativas trazidas já vinham no exercício de um pensamento tramado pelos seus saberes dentre muitas experiências vividas.

O envolvimento com a pesquisa (auto) biográfica leva o Gepeis a inscrever-se nessa vertente, desviando-se pelas histórias de professores nas escolas de Santa Maria/RS e da região. Além das práticas de sala de aula, os professores contam de si e como a vida abre os territórios de diferentes fases de suas histórias para dar sentido ao que constituem seus planejamentos em sua docência, suas preocupações, sua compreensão política, cheios de sentido: falam e ouvem suas apresentações, interpretando-as e reinventado-as. Abrem as portas de escola pelas chaves que receberam e nos conduzem pelos seus relatos. Reescrevemos histórias.

A proliferação da pesquisa narrativa no campo da educação no Brasil, datado nos anos noventa, inicia bem antes em outros países com o princípio da educação permanente e, relacionado à formação de adultos, como enfatiza Nóvoa. Os chamados para pensar a educação no Brasil até os anos noventa estavam muito limitados às leituras liberadas a serem feitas e que se detivessem às práticas escolares.

Esta inicia-se na transição dos anos 60 para os anos 70, referindo o sucesso que então conheceu o conceito de Educação Permanente. Ele era portador de uma crítica ao 'modelo escolar', deslocando a formação de uma idade específica (a infância) para todas as idades da vida e de um lugar concreto (a escola) para um conjunto de espaços sociais e culturais. (NÓVOA, 2004, p. 13)

As histórias dos professores nos levaram a refazer a história aqui. Aproveitamos a possibilidade de uma pesquisa que considera as ponderações dos professores ao contarem-se: a vida passava por fatos que, se corriqueiros e já vividos, agora poderiam ser reunidos em um álbum de recordações, que compunham cenários com muitas aprendizagens - que poderiam ser deixadas escritas, gravadas, anunciadas. Não só no Brasil, mas as lições com as histórias que os adultos contavam, aqui chegaram e também em outros territórios passava a dar novos contornos de pesquisa lá.

No conjunto das 'saídas' que esta reflexão foi tendo, vale a pena assinalar o aparecimento das 'histórias de vida' e o seu desenvolvimento nos espaços de formação de adultos. A equipa de Pierre Dominicé, na Universidade de Genebra, de que Marie-Christine Josso fez parte, foi um dos polos principais deste movimento nos países francófonos. Por uma via distinta, com origem em John Dewey e nas leituras que dele fez Donald Schon, também nos Estados Unidos da América se equacionavam as questões da experiência e da reflexão. Um pouco mais tarde, Mathias Finger e eu próprio, que tínhamos sido alunos de Pierre Dominicé no início dos anos 80 , publicávamos em Portugal uma colectânea de textos, 0 método (auto)biográfico e a formação que reunia muitos dos autores de referência dos dois lados do Atlântico. (NÓVOA, 2004, p. 13)

A escola que passava por um momento que precisava olhar para si, olhou para seus professores que atravessava os tempos para ver em quem se constituía esse corpo docente. Um grupo grande de mulheres que foram fazer a educação fora de casa, foram para a escola. Se esses fazeres foram, em parte, olhados e pensados como "formação de adultos", em parte como "questões da experiência e da reflexão", o que se percebeu foi a demanda por uma investigação que dava a conhecer quem a ela se expunha.

Ao fazer pesquisa conhecendo vidas, consideramos o tanto de forças que nos levam a trilhar caminhos e o quanto delegamos espaço ao fazer cotidiano. Inspirados em Serres (1990) que propõe pensar a aprendizagem também como errância, podemos nos dispersar em alguns pontos que julgamos pertinentes a uma 
reflexão avaliativa. Esse movimento pressupõe estranharmos o que vimos produzindo para que a pergunta: para que serve esse tipo de pesquisa em educação? - possa ter reverberação num movimento instituído nos nossos países.

O primeiro ponto que queremos trazer, e, não necessariamente no caráter de importância, poderia ser o desdobramento das nossas pesquisas autobiográficas na vida e nas práticas dos professores. Quando elegemos, um outro contrato de investigação, que não o da pesquisa sobre professores, mas com eles, já colocamos a produção do saber docente (TARDIF, 2012) em compartilhamento. Assumimos que os professores têm força em seu fazer e são reconhecidos pelo que contam, narrando seus fazeres e processos formativos, dando à apreciação os sentidos que identificam em sua profissão.

Tivemos, mas talvez, pudéssemos ainda dizer, temos, por ainda não poder conjugar no pretérito, uma prática que se configurou na lógica de [uma forma de] fazer pesquisa em que expressões emergiram, nos textos das análises utilizadas, como quem apenas de fora se punha a pressupor o que o professor fazia. Expressões entendidas como: descobrir "mazelas", conhecer "práticas heterônomas", que, ao fim e ao cabo, colocam os pesquisadores na posição de juízes, analisando práticas escolares e de seus professores. Estas questões nos provocaram repensar. 0 que conseguimos sedimentar na cultura docente com outras práticas de investigação?

Talvez, o fortalecimento do imaginário que o saber dos especialistas tivesse mais valor, mais consistência, poderia ter passado mais facilmente se não tivéssemos trazidos as pessoas para as suas histórias. Pesquisas que se estabelecem em percentuais calculáveis, anonimatos impessoais, possibilitam um afastamento que mostra claramente a falta de diá- logo entre quem produz os questionamentos de pesquisa e quem os responde. A postura de quem dá a chance ao entrevistado para falar sobre práticas que se produzem na escolas e na docência, passa a ser a de ouvir outras possiveis respostas.

Talvez, tenhamos, na contramão da produção internacional e nacional, a defesa da profissão docente a partir de um repertório de saberes próprios, despotencializado de suas autorias, a necessidade de reconhecimento. $A$ legitimidade das narrativas nos colocaram em contato com experiências vividas e, que, quando contadas a um outro com uma escuta sensivel, acabavam por (res)significar através do trabalho da memória sua reconstrução a partir do presente.

Uma memória que lembra, que reconstrói, que esquece e que inventa, torna-se potente de uma imaginação criadora (CASTORIADIS, 2004). Um trabalho que a narrativa pode provocar, onde como dispositivo, a imaginação é articuladora do pensar para criar, não como o novo, mas sustentáculo potente de sentidos para seus fazeres docentes diários, o vivido toma sentidos para si e se reescreve. Quando propomos que aquele que se conta, possa trazer seus sonhos, seus devaneios, o vivido pode tomar formas ainda não experimentadas para se insurgir.

Ao respondermos que a narrativa autobiográfica convoca o sujeito à reconstrução de seus trajetos e repertórios, exercita um trabatho de memória, terapêutico por excelência, que acarreta a reconstrução narrativa do pensar sobre si. De errâncias, a conhecer outros territórios que não apenas o anunciado em uma formação limitadora, as aprendizagens foram sendo tomadas em acertos até tentativas de se pensar outras possibilidades em educação. Transitar por territórios de teorias conhecidas a se intentar por novos trajetos de eventualidades pedagógicas, requer um com- 
passo de coragem política a tracejar rumos sem certezas.

Em outros trabalhos aproximamos essa reflexão do pensar sobre si e um tempo para si, mobilizado pela experiência formadora, com a noção de cuidado de si, recuperada por Michel Foucault (2004), na sua estética da existência. Este cuidado que olha para si, enquanto é olhado também pelo outro, implica em certas técnicas como uma "arte de conduta", que as pessoas realizam de forma consciente, operando sobre si próprias, na perspectiva de constituição de um modo de ser. Enquanto se experimenta em um viver, se igual a todos, se questiona; se diferente de todos, se questiona: quando saber que seu viver produziu o cuidado para uma existência que provoca encontrar sentidos?

Num processo de reconstrução a partir dos povos antigos, por exemplo, os gregos, o exercício de preceitos como "conhece-te a ti mesmo" e, mais radicalmente, "ocupa-te de ti mesmo", cria o conceito de epiméleia heautoú, o cuidado de si, que Foucault traz à pauta para relembrar o já experimentado como forma de vida (RABINOW; DREYFUS, 1995, p. 268). A valia implicada a "trabalhar ou estar preocupado com alguma coisa" também atingiu os corpos de professores, que entraram em lógicas produtivistas, conteudistas. Há na genealogia foucaultiana uma problematização sobre essas técnicas, que podem ser revistas onde houver mais diálogos, cartas e outros tipos de escritas, como técnicas de si, não para serem como escrutínio de uma vida, mas um cuidado sobre si.

Para esta forma de fazer pesquisa, um tempo foi exigido: o que se maleabiliza em formação, em pesquisa formação. Esse exercício reflexivo, chamado por Josso (2004) de experiência formadora, deu tempo para passar a conversar sobre a vida, e que poderia ser a partir de jogos, brincadeiras, atuações (LORENZONI, 2018), desde que se permitisse um tempo para falar de si. Quando apresentamos as pesquisas, querer saber quais foram os "resultados" passa por respostas que afirmam sobre um caráter não quantitativo ou de produtos visiveis, mas fala de possiveis olhares que enxergam diferente depois de se contarem.

Percorrer a pesquisa em educação rendeu aprendizagens que não poderiam mais estar em um processo de criação solitário. Fomos construindo pesquisas coletivas e individuais (mas são isoladas) que se valeram do campo autobiográfico para uma aproximação dos imaginários construídos nos trajetos formativos das práticas educativas. Tramamos estudos em como fazer pesquisa com suas determinantes, que se refaziam enquanto a pesquisa com Histórias de Vida se compunha, também a partir das pistas de quem se fazia entrevistador junto aos que aceitavam contar seus relatos em narrativas.

Adentramos em um campo de representações, criadas pelas instituições que nos mostraram diferenças em tomar a História de Vida e os recortes propostos, tanto na Biografia Educativa (DOMINICÉ, 1988; JOSSO, 1988) como na Narrativa de Formação. A Biografia Educativa, por exemplo, não é uma história global da vida, mas um recorte de seus processos formativos. Didaticamente, Pereira aponta as fases desse trabalho dizendo que

A primeira consiste em um trabalho introspectivo, uma atenção interior que tem por objetivo desvelar como me tornei no que sou e como tenho eu as ideias que tenho. (id., ibid,: 41). A segunda supõe um distanciamento de si para ordenação do percurso de formação numa narrativa periodizada, considerada (a ordenação) um trabalho simultaneamente individual e autopoiético e obra coletiva (id.,ibid,: 43). Por fim, a terceira etapa consiste numa reflexão que visa a explicitação dos fios condutores que permitem compreender os encadeamentos, dos períodos entre eles, permitindo por um lado, compreender a dinâmica do sujeito na sua ma- 
neira de fazer escolhas ou de se deixar ir e, por outro lado, caracterizar os temas com os quais o sujeito entrou em confronto nas suas escolhas, orientações e reações. (PEREIRA, 2010, p. 45 - Grifos do autor)

Nesse movimento intitulado por Josso (1988) de "momentos charneira", importantes no trabalho sobre si, individual e, posteriormente, na socialização coletiva, muitos se reconhecem na fala do outro. Essa experiência que a autora chamou de formadora, implica em um processo reflexivo a partir do movimento de "caminhar para si" - marcante aos estudiosos que consideram esta formação parte da pesquisa que se constitui ao se conhecer vidas.

Um segundo elemento diz respeito a como efetivamos uma circularidade em espiral, das narrativas produzidas com os professores. Provocar que voltem às suas reflexões, a partir de continuidades e descontinuidades dos relatos, são exercícios que movimentam um tempo pouco possível no diário das práticas escolares. Organizamos essas narrativas, numa perspectiva de implicarmo-nos com elas e, buscarmos juntos com os (co)autores a compreensão de como cada singular-coletivo chegou até onde pode narrar e, que consequências socioculturais e históricas essas narrativas trazem ao cenário da formação e das práticas docentes.

Onde nessas viagens erramos, onde paramos e onde poderíamos retomar, tendo em mente que a pesquisa tem a responder à pergunta da relevância? o que seguimos e o que deixamos na errância? Há pesquisas produzidas em nossos territórios que, mesmo num trabalho analítico, os autores se furtam de expandir o contexto de fala, para além daquilo que foi dito. Da análise do vivido singularmente, não podemos ficar no relato singular, sem conseguir entendê-lo como parte de um tempo, de um lugar, de uma biopolítica.
Mostrar as continuidades e descontinuidades nas práticas discursivas dos sujeitos que participam das nossas pesquisas, implica o que Delory-Momberger chamou de dupla hermenêutica. 0 narrador ao sistematizar seu material vivido, elegendo o que deseja socializar à uma investigação, já realiza um primeiro movimento hermenêutico. 0 pesquisador (com)partilha da experiência narrada e é convidado, num trabalho analítico, ao exercício da ampliação do narrado, mostrando, no trabalho hermenêutico, os contextos de produção de fala ou de escrita.

\section{As experiências que ficaram: histórias que se contam}

Nas experiências com a pesquisa histórica e a reconstrução das lembranças pelo trabalho da memória, aprendemos que uma vida - singularmente escolhida para ser narrada - é um exemplar de um tempo ou para além dele: um vivido que potencializa pensar tempos, espaços e acontecimentos. A vida que alguém traz, inscrito nela um contexto socio-histórico e cultural a ser conhecido pela oralidade, se tenta uma transcrição. Uma vida que se não for contada, nunca saberemos sobre imaginários instituídos e instituintes de uma época. Uma vida que traz a história das mentalidades, dos comportamentos do tempo vivido, ou, para além dele.

Nessa perspectiva, acrescentamos às aprendizagens coletivas do GEPEIS os estudos investigativos com a pesquisa a partir das histórias de vida, agora não mais apenas transcritas, mas também filmadas. A produção da narrativa de Maria Luisa, transformando-a num documentário, como uma produção audiovisual, traz o desafio para as instituições educativas olhar para os comportamentos sociais [vivos]. Marias e Luisas, a narrativa de uma transexual militante das causas LGBT+, da cidade de São Borja, fronteira do Rio Grande do 
Sul com a Argentina, trouxe, quando aluna do Instituto Federal Farroupilha, a necessidade de reconhecimento normativo do nome social.

Na concepção da História Oral, de reconstruirmos histórias que não seriam contadas se não emprestássemos nossos corpos para que outros tivessem visibilidade dentro da academia, produzimos a narrativa oral, transcrita e roteirizada como documentário. Conhecer imaginários pela narrativa do vivido é provocar a aproximação de uma história contada por quem a viveu. As histórias de Maria Luisa estavam nas invisibilidades que continuamos negando nas salas de aula quando buscamos enquadrá-las nos padrões de vida e de trabatho que já conhecemos e que, pela força da narrativa, evidenciam-se e acabam por provocar deslocamentos, desassossegos, outros pensamentos.

Diante disso, falar em narrativa biográfica, pelas palavras de Delory-Momberger (2008, p. 61), é considerar que "a narrativa biográfica do outro é assim um dos lugares onde experimentamos nossa própria construção biográfica, onde ela pode deslocar-se, reconfigurar-se, alargar seu horizonte: onde ela se põe à prova como escrita de si". O alargamento de horizontes, na ampliação de repertórios, com relação a temas como etnias, classes sociais, gênero e diversidade sexual, podem ser experimentados, pela aproximação de narrativas que não têm ainda um espaço de voz e de escrita nas pesquisas acadêmicas.

Temos nos aproximado de professores que contam suas memórias em muitas narrativas, como incentivadores e promotores a experimentarem-se autobiógrafos. E, ao colocar nossos convidados na condição de pesquisadores de si, aprendemos com eles os outros modos de viver, de sentir, de decidir sobre sua vida erótica e sexual. Nessa experiência formativa acionamos, segundo Delory-Momberger, uma compreensão hermenêutica da "história de vida".
O trabalho da reflexividade biográfica é de natureza hermenêutica; assim como o hermeneuta considera o texto como totalidade com a qual se relaciona cada uma de suas partes, o autobiógrafo representa para si sua vida como um todo unitário e estruturado com o qual relaciona os momentos de sua existência. (DELORYMOMBERGER, 2008, p. 57)

Nas narrativas de Maria Luisa tivemos acesso a dois momentos de um todo unitário para ela, como narradora. Para nós, pesquisadores e formadores nos espaços educacionais, os fragmentos de relatos vão se tramando e tomam sentido; são fios que fomos juntando e dispondo correspondência ao associar a tempos políticos e eventos culturais. Tivemos acesso a uma primeira narrativa mais ensimesmada, necessária para a autora, num processo de ressignificação das experiências vividas. A segunda, já de uma outra perspectiva ética e estética, já passado um certo tempo entre uma narrativa e outra, um relato militante. Por isso, os encontros foram importantes: se abriram a dar condições em traçar um roteiro para a filmagem.

A narrativa de uma militante pelas políticas das transsexuais e dos travestis, sua vida como prostituta foi trazida em um relato de confiança ao grupo, que produziu um documentário referência em nossos projetos. Mais que uma história de vida, transformou-se em denúncia da precariedade da cidadania das transexuais numa sociedade que privilegia a heteronormatividade como padrão. Um relato que desloca e que provoca pensar naqueles que insistem numa narrativa neoliberal, de dizer que as pessoas não conseguem um trabalho, uma ocupação, um emprego porque não têm vontade ou não se esforçam.

$\mathrm{Na}$ produção audiovisual como pesquisa em educação também temos feito incursões significativas no espaço autobiográfico (ARFU$\mathrm{CH}, 2010$, p. 16): “horizonte de inteligibilidade e não como mera somatória de gêneros já con- 
formados em outro lugar". Ao nos aproximarmos daquilo que se convencionou pensar no auto, como uma narrativa de um eu que emerge ambíguo, se mostra na reconstrução de um tempo passado, de um tempo vivido, que não alcança os preceitos de invasão da vida intima, privada - tão aclamada por estes tempos sombrios que confundem figuras e espaços do público e do privado.

No espaço autobiográfico importa que, num exercício de alteridade, outros corpos utilizem os nossos para se contar, porque como afirma Cecília Meireles (2010), uma vida só vale a pena, se pode ser reinventada. Se também com as narrativas pudermos desassossegar e afetar corpos desanimados, cansados, precarizados na sua cidadania, produzimos um movimento ético e estético de valorização de outras subjetividades. Outras formas de viver, outras formas de ser professor nesses tempos sombrosos, parecem conseguir emergir e respirar em uma forma que vem de saber das forças resistentes que moram em si.

Como narradores, pesquisadores de si e do outro, os professores valorizam as narrativas, salientando que "O princípio ético orientador das pesquisas com histórias de vida é que as narrativas da experiência, longe de comunicar o que já se sabe, constituem-se verdadeiros processos de descoberta e reinvenção de si" (PASSEGGI; SOUZA, 2017, p. 13). Movimentamos no imaginário social sempre com a tensão que o instituído carrega, mas não nos paralisa. Ao contrário, nos mobiliza. Mobiliza a pensar outras formas, outros comportamentos, outras instituições. Nesse movimento, a narrativa do vivido toma força de memória e de possibilidade de ir inventando um outro presente.

\section{Referências}

ABRAHÃO, Maria Helena Menna Barreto. Pesquisa (auto)biográfica - tempo, memórias e narrativas. In: ABRAHÃO, Maria Helena Menna Barreto. A aventura (auto)biográfica: teoria \& empiria. Porto Alegre: EDIPUCRS, 2004, p.201-224.

ARFUCH, Leonor. O Espaço Biográfico. Dilemas da Subjetividade Contemporânea: EdUERJ, 2010.

BARBIER, René. A pesquisa-ação. Tradução de Lucie Didio. Brasília (DF): Liber Livro, 2007.

CANETTI, E. A língua absolvida: história de uma juventude. Tradução de Kurt Jahn. São Paulo: Companhia das Letras, 2010.

CASTORIADIS, C. As encruzilhadas do labirinto VI figuras do pensável. Rio de Janeiro: Civilização Brasileira, 2004

CASTORIADIS, Cornelius. A instituição imaginária da sociedade. Tradução de Guy Reynaud. Rio de Janeiro: Paz e Terra, 1982.

DELORY-MOMBERGER, Christine. Biografia e educação: figuras do indivíduo-projeto. Trad. de Maria da Conceição Passeggi, João Gomes da Silva Neto, Luiz Passeggi. Natal, RN: EDUFRN; São Paulo: Paulus, 2008.

DOMINICÉ, Pierre. A biografia educativa: instrumento de investigação para a educação de adultos. In: NÓVOA, António; FINGER, Mathias. 0 método (auto) biográfico e a formação. Lisboa: MS/DRHS/CFAP, 1988, p. 99-106.

FOUCAULT, Michel. Hermenêutica do Sujeito. São Paulo: Martins Fontes, 2004.

JOSSO, Marie-Christine. Da formação do sujeito ao sujeito da formação. In: NÓVOA, António; FINGER, Mathias. (Org.) 0 método (auto) biográfico e a formação. Lisboa: MS. DRHS.CFAP, 1988, p. 37-50.

JOSSO, Marie-Christine. Experiências de vida e Formação. São Paulo: Ed. Cortez, 2004.

LORENZONI, Cândice Moura. Ser artista professor: tramas, imaginários e poéticas em jogo nos espaços de atuação-formação. 2018. 344p. Tese (Doutorado em Educação). Universidade Federal de Santa Maria, UFSM, Santa Maria, RS, 2018. Disponivel em: <https:// repositorio.ufsm.br/bitstream/handle/1/15683/TES_ PPGEDUCACAO_2018_LORENZONI_CANDICE.pdf?sequence=1\&isAllowed=y>. Acesso em: 22 oct. 2019. 
MARIAS e Luisas. Direção: Valeska Fortes de Oliveira. Brasil: Gepeis, 2018. (26min52seg). Disponível em: <https:// normas-abnt.espm.br/index.php?title=V\%C3\%ADdeo/Filme>. Acesso em: 22 oct. 2019.

MEIRELES, Cecília. Cecília de Bolso. Uma Antologia Poética. Porto Alegre, RS: LP\&M, 2010.

MIORANDO, Tania Micheline. Ir ao Cinema: a Formação Inicial de Professores e o instituinte ético-estético em Educação nos Processos Formativos Docentes. 2018. 150p. Tese (Doutorado em Educação). Universidade Federal de Santa Maria, UFSM, Santa Maria, RS, 2018. Disponível em: <https: / / repositorio. ufsm.br/handle/1/16244>. Acesso em: 22 oct. 2019.

MORIN, Edgar. Os sete saberes necessários à educação do futuro. São Paulo: Cortez;Unesco, 2001.

NÓVOA, A. (Org.) Vidas de professores. Porto: Porto Editora, 1995.

NÓVOA, António (Org.). Vidas de professores. Porto: Porto Editora, 1992.

NÓVOA, António. Em busca da Liberdade nas universidades: Para que serve a investigação em Educação? In: Revista Lusófona de Educação, 28, 2014. Disponivel em: <https://revistas.ulusofona.pt/ index.php/rleducacao/article/view/4936>. Acesso em: 22 oct. 2019.

NÓVOA, António. Em busca da liberdade nas universidades: para que serve a pesquisa em educação?. Educ. Pesqui., São Paulo , v. 41, n. 1, p. 263-272, mar. 2015. Disponivel em http://www. scielo.br/scielo.php?script=sci_arttext\&pi$d=S 1517-97022015000100263 \& \operatorname{lng}=p t \& n r m=i s o$ Acessos em: 22 oct. 2019.

NÓVOA, Antonio. Prefácio. In: ABRAHÃO, Maria Helena M. B. (org.) História e Histórias de vida: destacados educadores fazem a história da educação riograndense. Porto Alegre: EDIPUCRS, 2004, p. 7-12.

NÓVOA, António; FINGER, Matthias (Org.). 0 método (auto)biográfico e a formação. Lisboa: Ministério da Saúde, Departamento dos Recursos Humanos da Saúde, 1988.

OLIVEIRA, Valeska F. de (Org.). Imagens de Profes- sor: significações do trabalho docente. ljuí : Ed. UNIJUí, 2000.

OLIVEIRA; Valeska Fortes de. Movimentos entre Verbetes, Significações e Funcionalidades: a formação e a docência na sociedade contemporânea. In: MIORANDO, Tania M. SILVA, Jacqueline Silva da. (Orgs). Formação de Professores nas Trilhas do Parfor. Lajeado/RS: Editora da Univates, 2016, p. 9-18. Disponível em <https://www.univates.br/editora-univates/media/publicacoes/163/pdf_163.pdf>. Acesso em 22 out 2019.

PASSEGGI, Maria da Conceição; SOUZA, Elizeu Clementino (Org.) (Auto)Biografia: formação, territórios e saberes. São Paulo: Paulus; Natal: EDUFRN, 2008.

PASSEGGI, Maria da Conceição; SOUZA, Elizeu Clementino de. O Movimento (Auto) Biográfico no Brasil: esboço de suas configurações no Campo Educacional. Investigación Cualitativa, Madri, v.2, n.1, p. 06-26, 2017. Disponível em: <https://ojs.revistainvestigacioncualitativa.com/index.php/ric/article/ view/56/36>. Acesso em: 22 oct. 2019.

PEREIRA, Marcos Villela. Estética da Professoralidade: Um estudo crítico sobre a formação do professor. Santa Maria: Editora UFSM, 2013.

PEREIRA, Marcos Villela. Sobre histórias de vida e autoformação: um enfoque ético e estético. In: ABRAHÃO, Maria Helena Menna Barreto (org.) (Auto) Biografia e Formação Humana. Porto Alegre: EDIPUCRS, 2010, p. 123-138.

RABINOW, Paul; DREYFUS, Hubert. Michel Foucault, uma trajetória filosófica: para além do estruturalismo e da hermenêutica. Rio de Janeiro: Forense Universitária, 1995.

SERRES, Michel. 0 Terceiro Instruído. Trad. Serafim Ferreira. Lisboa: Piaget, 1993.

TARDIF, Maurice. Saberes docentes e formação pro-

fissional. 13. ed. Petrópolis: Vozes, 2012.

Recebido em: 14.11.2019

Revisado em: 27.03.2020

Aprovado em: 30.03 .2020 
Valeska Fortes de Oliveira é Doutora em Educação pela Universidade Federal do Rio Grande do Sul - UFRGS. Mestre em Educação pela Universidade Federal de Santa Maria - UFSM. Professora Titular no Departamento de Fundamentos da Educação, Centro de Educação, Universidade Federal de Santa Maria - UFSM. E-mail: vfortesdeoliveira@gmail.com

Tania Micheline Miorando é Doutora em Educação pela Universidade Federal de Santa Maria - UFSM. Mestre em Educação pela Universidade Federal de Santa Maria - UFSM. Especialista em Educação de Surdos. Licenciada em Educação Especial/Hab. em Educação de Surdos. Professora Adjunta no Departamento de Educação Especial, Centro de Educação, Universidade Federal de Santa Maria - UFSM. E-mail: tmiorando@gmail.com 